\title{
A general approach to assess hydro-mechanical changes of natural clay barriers due to physico-chemical interactions with radwaste in deep disposal sites
}

\author{
Robrecht M. Schmitz *, Christian Schroeder, Robert Charlier \\ Chemin des Chevreuils 1 B52, Geomac, Université de Liège, B4000 Liège, Belgium
}

Received 1 August 2005; received in revised form 16 October 2005; accepted 8 January 2006

Available online 1 November 2006

\begin{abstract}
Radwaste must be isolated from the biosphere for a long periods. To isolate waste, engineered clay barriers can be constructed. The functional life of such engineered barriers must be much longer (factor 100-1000) than that of more common engineered structures. Can the responsible engineer guarantee a functional life of several thousand years? Probably not, therefore waste like radwaste is stored at great depths, in a combination of geological and engineered barriers. During the storage period the waste itself (radiation) or derived products (oxidation of containers) can interact with the engineered and geological clay barriers. In this contribution it is discussed how such interactions affect the hydro-mechanical properties of clay barriers. First some examples are given that show how properties of clays change at surface conditions if clays are exposed to typical waste products like different cations. Thereafter a method is proposed to classify the potential of hydro-mechanical modifications at three different scales: the particle level, the interlayer level and the tetrahedral-octahedral level. Next it is explained why the reactivity of clays at depth during long-term waste isolation is different (smaller) from the better known reactivity of clays at the surface. Instead of directing too much attention to such well known interactions, the focus for a safe deep disposal of radwaste should be directed to reactions that play a role at depth if, e.g. damage due to radiation occurs. Only if such reactions can be excluded, a safe storage of waste is possible.
\end{abstract}

(c) 2006 Elsevier Ltd. All rights reserved.

Keywords: Boom clay; Hydraulic conductivity; Mineral alteration; Waste disposal

\section{Introduction}

Since engineered structures normally have a functional life of only 100 years, natural barriers have to be incorporated into the design of long-term waste disposal sites. Thick clay formations can constitute such natural barriers. Once a suitable location within the formation has been selected on the basis of its geomechanical and hydrogeological properties, it must be guaranteed that these properties do not unfavourably alter when the clay is contacted by leachates or radiation produced by the waste itself or oxidation products originating from waste containers. In this

\footnotetext{
${ }^{*}$ Corresponding author.

E-mail address: Schmitz.Robrecht@VDI.de (R.M. Schmitz).
}

contribution a general approach is presented to analyse the effect of physico-chemical reactions on the hydro-mechanical properties of clays.

\section{Reactivity of clays at surface conditions}

The ability of clays to change their hydro-mechanical properties can be demonstrated by plotting the changes in liquid limit (LL) of the same clay when exposed to different concentrations of salt. In Fig. 1 the liquid limit of two different clays containing Smectite is plotted as a function of the concentration of different salt solutions. If large changes in liquid limit occur it has been demonstrated that other properties (friction angle, consolidation coefficient, hydraulic conductivity) change as well (Mitchell, 1993). 


\section{Nomenclature}

BS the basal spacing of an oriented clay sample. These values can be measured or can be found in literature for several clay types (e.g. Mitchell, 1993) $(\AA)$

CEMC concentration equivalent monovalent cations (mol/unit volume)

$\mathrm{CEMC}_{\text {ini }}$ concentration equivalent monovalent cations of the fluid contained in the clay before permeation (mol/unit volume)

$\mathrm{CEMC}_{\mathrm{fin}}$ concentration equivalent monovalent cations of a leachate (mol/unit volume)

EBS equivalent basal spacing, defined in: Schmitz et al., 2004a (unit length)

EBS $_{\text {ini }}$ equivalent basal spacing before fluid/leachate contact $(\AA)$

EBS $_{\text {fin }}$ equivalent basal spacing after fluid/leachate contact $(\AA)$

$\mathrm{h}_{\text {TOT }} \quad$ thickness of a TOT/TO-layer $(\AA)$

LL liquid limit (\% fluid content)
TCF total amount of clay minerals ( $\%$ total mass sample)

$\mathrm{TCF}_{\text {ini }}$ total amount of clay minerals in a clay sample before fluid/leachate contact (\% total mass sample)

$\mathrm{TCF}_{\text {fin }}$ total amount of clay minerals in a clay sample after fluid/leachate contact (\% total mass sample)

TO-layer tetrahedral-octahedral layer, the basic unit of two-layer minerals like Kaolinite

TOT-layer tetrahedral-octahedral-tetrahedral-layer, the basic unit of three-layer minerals like Smectite and Illite

XRD X-ray diffraction

$\varepsilon^{\prime} \quad$ relative dielectric constant (water $=80$; etha$\mathrm{nol}=25$; oil $=2(-))$

$\varepsilon_{\text {ini }}^{\prime} \quad$ relative dielectric constant of the fluid contained in the clay before permeation (-)

$\varepsilon_{\text {fin }}^{\prime} \quad$ relative dielectric constant of the leachate $(-)$

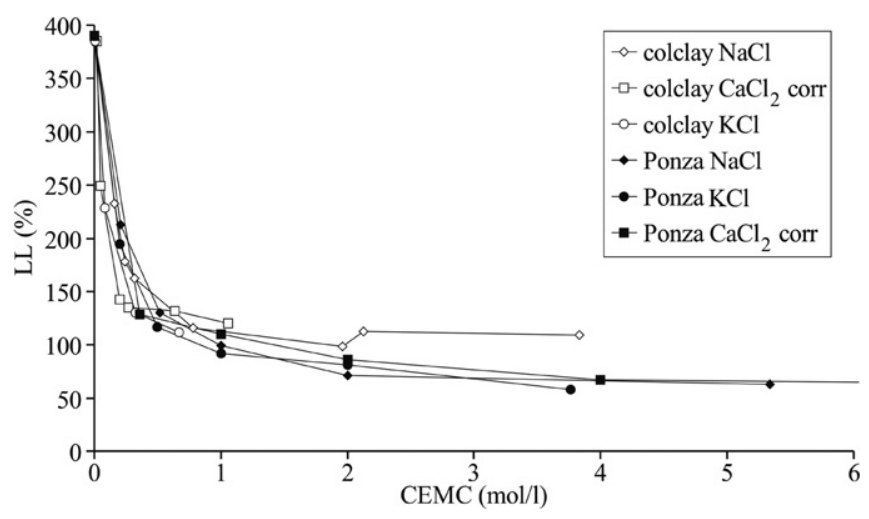

Fig. 1. Large changes in liquid limit (LL) occur if salt solutions are added to clays. On the horizontal axis the concentration of different salt solutions is plotted, on the vertical axis the liquid limit. The salt concentration is expressed as equivalent amount of monovalent cations (Source: di Maio, 1996; van Paassen, 2002; Schmitz and van Paassen, 2003).

The modifications in liquid limit are related to the combined effect of changes in the thickness of the diffuse double layer of clays (on the particle level) and more important, the interlayer reactivity of clays (on the interlayer level). This is shown in Fig. 2. Depending on the concentration and the type of cations, the distance between the TOT-layers (Smectite) varies as a function of the concentration (expressed as CEMC, the concentration of an equivalent amount of cations). Note that in presence of $\mathrm{K}^{+}$cations the distance between the TOT-layers or entire particles approaches $0 \AA$ ("Illitisation"). The dashed line shows a derivation of the interlayer spacing $\left(\mathrm{BS}-\mathrm{h}_{\mathrm{TOT}}\right)$-salt concentration relationship based on the equivalent basal spacing

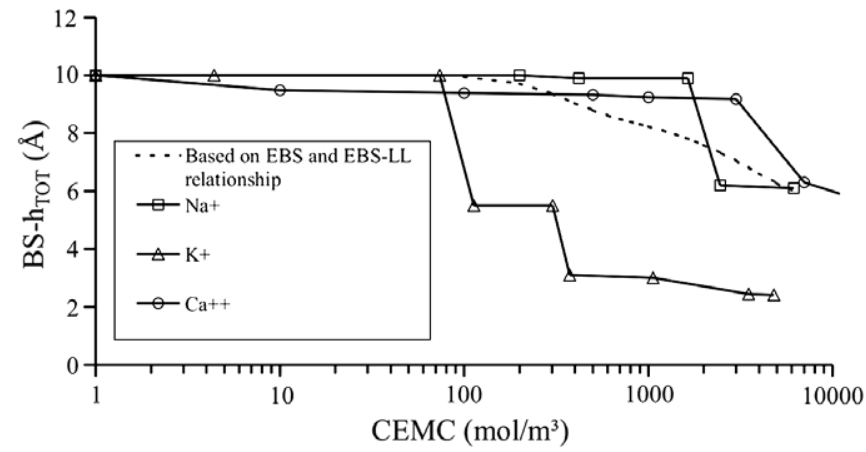

Fig. 2. Depending on the concentration and the type of cations, the distance between the TOT-layers (Smectite) varies as a function of the concentration (expressed as CEMC, the concentration of an equivalent amount of cations). Data-set: Lagaly (1993). The dashed line is constructed on the basis of the relationship between the LL and the interlayer distance established by Schmitz (2004) and the relationship between the LL and the CEMC shown in Fig. 1 [Figure from Schmitz (2004)].

(EBS) theory, the relationship between the EBS and the LL, and the LL-salt concentration measurements shown in Fig. 1. Note the close resemblance to the X-ray diffraction (XRD) measurements by Lagaly (1993). This shows that the liquid limit depends on reactions on the interlayer and the particle level. Because effects on a lower level (here the interlayer level) are more powerful than alterations on a higher level (here represented by the particle level) reactions on the interlayer level may mask reactions on the particle level. The liquid limit depends thus strongly on the mineralogy and on the clay-fluid chemistry. Large changes (more than tens of \%) occur if substances enter the inter- 
layer space (i.e. a mineral alteration). Small changes occur if the fluid chemistry modifies the particle to particle arrangement by varying in double layer thickness (less than tens of $\%$ ).

Large changes in LL shown in Figs. 1 and 2 occur if cations, e.g. produced by oxidation of waste containers access the clay. The liquid limit is reduced but the clay minerals remain clay minerals. Even larger changes occur if the clay structure is changed, e.g. destruction of the tetrahedraloctahedral sheets. These reactions are not as frequent as changes in interlayer spacing and double layer thickness, but can occur on the long-term i.e. a long history of subsequent physical and chemical interactions with percolating fluids, stress and clays are needed. An example of the latter was recognised in clay barriers to isolate domestic waste in landfills (Schmitz, 2004). In underground waste disposal site the requested isolation times are even longer than in domestic waste confinement and therefore such reactions cannot be excluded. In addition radiation can lead to TOT-layer destruction.

As shown above clays are reactive and changes in hydromechanical properties occur easily but which changes can be expected? Can we predict the order of magnitude of the changes? To answer these questions we first have to classify the potential of hydro-mechanical modifications.

\section{Classification of the potential of hydro-mechanical modifications}

Depending on the scale, different alteration processes are important (Table 1). Therefore a three-scale approach is followed: on scale 1, tetrahedral-octahedral sheets are concerned; on scale 2, the interlayers; and on scale 3, the clay particles.

\subsection{Tetrahedral-octahedral level}

This is the smallest level at which clay minerals are analysed. The general opinion found in literature dealing with clay barriers and landfill leachates is that the layer silicates remain intact (e.g. an Illite remains an Illite, and a Kaolinite remains a Kaolinite), see Kohler (1988), Schmitz et al. (2003b) and the literature overviews by Prinz (1997) and Schmitz (2004). An example of a process in which damage of layer silicates occurs is the ripping of a tetrahedral sheet during kaolonitisation by transformation.

Table 1

The three different scales on which a waste-clay barrier interaction analysis should be based

\begin{tabular}{|c|c|c|c|}
\hline Level & $\begin{array}{l}\text { Tetrahedral- } \\
\text { octahedral sheets }\end{array}$ & Interlayers & Particles \\
\hline $\begin{array}{l}\text { Time needed for } \\
\text { alteration } \\
\text { in nature }\end{array}$ & $\begin{array}{l}\text { Several years } \\
\text { to centuries }\end{array}$ & $\begin{array}{l}\text { Diffusion } \\
\text { (lab sample) } \\
\text { months }\end{array}$ & $\begin{array}{l}\text { Flow } \\
\text { (lab sample) } \\
\text { weeks }\end{array}$ \\
\hline Scale & Ångströms & Nanometers & Micrometers \\
\hline
\end{tabular}

\subsection{Interlayer level}

In geotechnical terms the main difference between clay minerals is related to differences in interlayer space whatever their origin (Schmitz et al., 2004b). Clay mineralogists study this interlayer space in order to classify clay minerals by X-ray diffraction analysis. The appropriate way to introduce clay mineralogy to geotechnics is to analyse changes in EBS, equivalent basal spacing (Schmitz et al., 2002, 2003a, 2004).

\subsection{Particle level}

Reactions on the particle level are the most frequent, the fastest to accomplish (instantaneous when leachate arrive) and have the least impact on the geomechanical properties of clays. The double layer theory presents a valuable framework to analyse the changes in geomechanical properties upon clay-leachate contact on the particle level. The properties of the fluid that are taken into account are the concentration of cations and the relative dielectric constant. Other processes on the particle level not captured by the double layer theory are, e.g. the dissolution of calcitic cement and the oxidation of pyrites. The acids produced by the latter process influence reactions on the lower interlayer and TOT/TO level as well. As a result of dissolution of cement between the particles like, e.g. Calcite (Prinz, 1997), particles become free and the colloidal behaviour is changed (Komodromos and Göttner, 1988). Precipitation and dissolution of cementing agents should be analysed for each waste scenario separately, based on a detailed analysis of fluids contained in the engineered clay barrier, the geological barrier and possible oxidation products of waste containers.

\section{Methods to assess the potential to change hydro-mechanical properties}

This approach is based on the analyses of the occurrence of physico-chemical reactions on the three distinct levels mentioned above: the tetrahedral-octahedral layer (TOT/ TO) level, the interlayer level and the clay particle level (Table 1). Each level is characterised by different physical and chemical processes. These processes, related to a specific level, occur on different time scales and provoke modifications of the hydro-mechanical properties of different orders of magnitude. Physico-chemical reactions occur in natural or engineered clay barriers, if the ratios, shown in Table 2, expressing the state before storage and during/ after storage of waste, are unequal to unity. These ratios can easily be determined in the laboratory by doing a few tests (XRD, chemical analysis) on clay barrier material or using literature data representative of the properties before and after leachate contact.

The impact of physico-chemical processes on the geomechanical properties of clay increases in the order of the expressions (3), (2), (1). The degree, to which these ratios 
Table 2

If the following ratios change hydro-mechanical modifications of the clay barrier occur

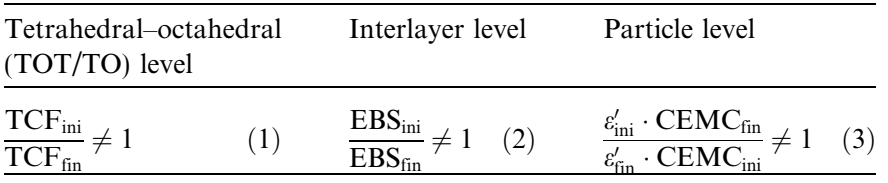

$\mathrm{TCF}=$ total clay fraction; EBS $=$ equivalent basal spacing; $\mathrm{CEMC}=$ concentration of an equivalent amount of cations in the fluid contained in the clay or the leachate; $\varepsilon^{\prime}=$ relative dielectric constant of the fluid contained in the clay or the leachate; ini = the initial situation before claywaste interaction; fin $=$ the situation after clay-leachate interaction. (For a complete description of the definition of variables see Schmitz et al. (2004c) or Schmitz (2004)).

change, depends on the accessibility of the structure of the clay, thus, the accessibility of interparticle space (particle level) interlayer space (interlayer level), and the damage that occurs to the tetrahedral and octahedral sheets of the clay minerals (TOT/TO level). The accessibility of the clay to waste products or to its derivatives depends on boundary conditions such as the effective stress. In the case of the boundary conditions in clay barriers confining surface repositories it has been shown for domestic waste surface landfills (Schmitz, 2004) that interlayers are not accessible on the short-term. Tetrahedral and octahedral sheets will change eventually but all reactivity, at least on short-term, is located in the interparticle spaces (particle level) in surface landfills.

Depending on the values determined for the three ratios given in Table 2, five different cases can be discerned:

Case (I) Ratios of expressions (1) and (2) much smaller than 1.

Physical properties. The initial material will become more clayey: larger liquid limit, larger plasticity index, lower friction angle, lower hydraulic conductivity, if the clay constituting the barrier is remoulded and reconsolidated during its functional life in situ or if the clay is remoulded before the test in the laboratory.

Recognisable. Increase of the total clay fraction in XRD plots or increase of the crystallinity of peaks characteristic of clays. Shift of clay peaks to higher basal spacing values. Increase of the liquid limit, increase of stickiness of the clay.

Case (II) Ratios of expressions (1) and (2) slightly smaller than 1, expression (3) much smaller than 1.

The difference in Atterberg limits and clay mineralogy are hardly measurable. Differences exist in the measured hydraulic conductivity for clay barriers, which will increase slightly (if under oedometric boundary conditions).

Case (III) Ratios equal to 1.

No physico-chemical changes occur, except for chemical-physical processes like dissolution or precipitation of cementing agents.
Case (IV) Ratios of expressions (1) and (2) slightly larger than 1, expression (3) much larger than 1.

The difference in Atterberg limits and clay mineralogy are hardly measurable. Differences exist in the measured hydraulic conductivity for clay barriers which will decrease slightly (if under oedometric boundary conditions).

Case (V) Ratios of expressions (1) and (2) much larger than 1.

Physical properties. The initial clay material will start to loose its clayey behaviour: lower liquid limit or no determination of liquid limit possible, lower plasticity index, higher friction angle, higher hydraulic conductivity, if the clay constituting the barrier is remoulded and reconsolidated during its functional life in situ or if the clay is remoulded before the test in the laboratory. Recognisable. Decrease of the total clay fraction in XRD plots or absence of peaks characteristic of clays or shift of basal spacings to lower values. Loss of cohesion of the clay. The clay starts to behave silt-like.

\section{Reactivity of clays at depths}

As discussed above clays are known to react with many substances and change herewith their hydro-mechanical properties at surface conditions. Do these reactions occur as well at depth, in a tunnel shaped underground repository? The major difference with surface waste confinement sites is the much higher stress level.

In a waste disposal site at $200 \mathrm{~m}$ depth the initial stress will mount to $\sim 4 \mathrm{MPa}$, the tangential stresses will even rise to $8 \mathrm{MPa}$ (see Fig. 3). In this paragraph the effect of an increase in the concentration of cations in the clay barrier by migration of $\mathrm{Fe}^{2+/ 3+}$ cations - originating from the metal containers confining the waste - into the clay formation will be studied as example (note that this is a defavourable case, the flow could as well be directed in the other sense). Because of the much higher effective stresses the interparticle accessibility (particle level) will be smaller with respect to surface repositories (this will be discussed in paragraph 5.1). An additional feature of large stress and especially stress anisotropy is the reorientation of clay particles (natural analogue: slate formation) from their original depositional orientation to an orientation perpendicular to the principal stress. In the literature reorientation of clay particles were observed at even lower stress levels, e.g. Morgenstern and Tchalenko (1967) and Schmitz $(2000,2004)$ on other clay types. Not only the interlayers are less accessible the influence of the thickness of the diffuse double layer is reduced as well. These aspects are now discussed for each level separately.

\subsection{Interlayer level}

In the case of deep seated disposal the inaccessibility on the interlayer space (interlayer level) is guaranteed by the 


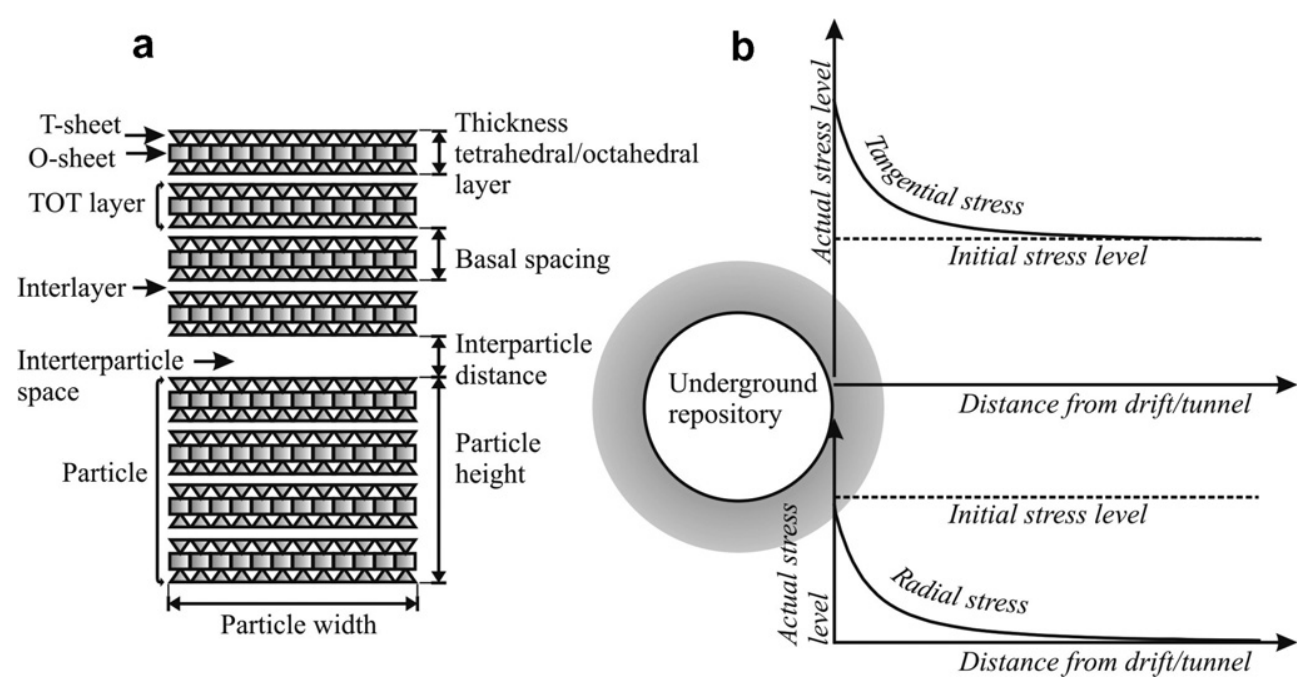

Fig. 3. (a) The natural clay barrier possesses structural characteristics (particle size, height, width and depth, orientation, number of layers per particle etc.) related to its sedimentological history. (b) Due to anthropogenic activity properties as orientation of clay particles can change due to the changing stress field while excavating the underground repository.
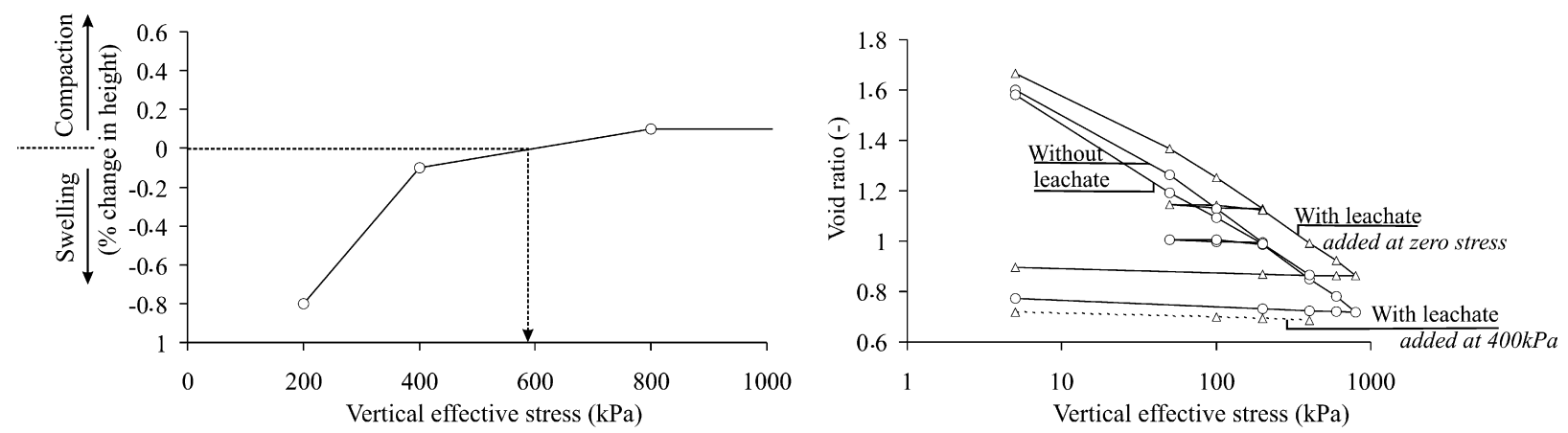

Fig. 4. Oedometer test results on samples from the Boom clay formation. An example of a clay formation considered as host rock for underground waste disposal.

high effective stresses, which will even increase after construction of the tunnel to confine the waste (see Fig. 4).

In Fig. 4 (left) the swelling of Boom clay after hydration is shown. Swelling - related to expansion of the interlayers and therefore interlayer reactivity - stops at a vertical stress of several hundreds of $\mathrm{kPa}$ (Müller-Vonmoos and Kohler, 1993). In Fig. 4 (right) oedometer tests on Boom clay show that at low stress levels there is a small difference in void ratio between the clays which were exposed to leachates at atmospheric pressures before the testing. This difference persists throughout the test although the compression index and swelling index are not affected. If leachate was added during the test this did not lead to any significant modification of the hydro-mechanical properties such as consolidation as a result of the decrease of interlayer distance. Tests on other clays with other leachates showed the same phenomenon (Schmitz, 2004). Both examples show that interlayer accessibility is low, even at stress levels of only a few hundred $\mathrm{kPa}$. Expression (2) (Table 2) will remain close to unity in these conditions.

\subsection{Particle level}

In contrast to slurries, in soils however the clay particle spacing is not only governed by the repulsion of double layers but additionally by external stresses. The relationship between repulsion i.e. swelling pressure and external stress has been described by Bolt (1956) and more recently by Mitchell (1993) and Fam and Dusseault (1999). The relation, given by these authors, showed that with pure mechanical loading the distance between clay particles changes under increasing normal stress, in a non-linear way resembling a hyperbola. A characteristic example is illustrated in Fig. 5. If the chemistry of the interparticle fluid changes (e.g. change in concentration of cations or changes in relative dielectric constant), the distance between the clay particles oriented perpendicular to the principal stress decreases at constant vertical stress (see the arrows in Fig. 5). If, in reaction to such chemical loading, equilibrium is reached and renewed pure mechanical loading takes place, another stress-displacement curve is 

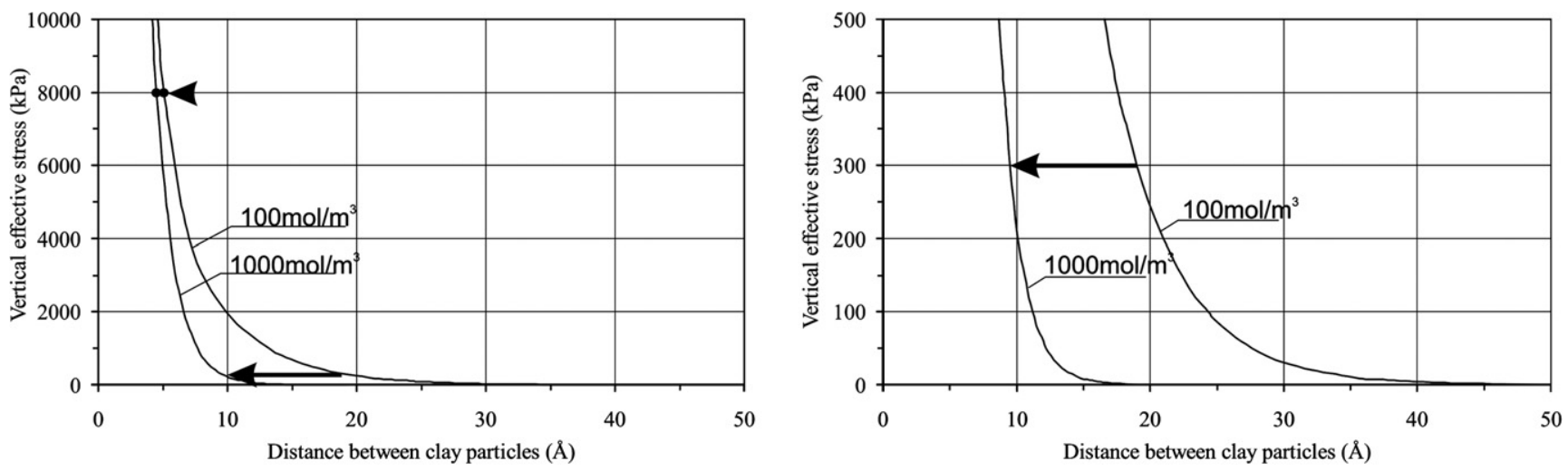

Fig. 5. Relationship between principal stress and distance between clay particles on the basis of the diffuse double layer theory. If the initial amount of $\mathrm{Fe}^{2+/ 3+}$ cations increases from $100 \mathrm{~mol} / \mathrm{m}^{3}$ to $1000 \mathrm{~mol} / \mathrm{m}^{3}$ clay particles can get closer to each other at the same stress level. This effect is larger at lower stress levels such as these occur in domestic waste landfills (lower arrow in the figure on the left and the figure on the right) than at higher stress levels such as these occur in deep seated waste disposal sites (figure on the left: upper arrow).

followed. Imagine that the initial amount of cations is $100 \mathrm{~mol} / \mathrm{m}^{3}$. If this value is increased by a factor 10 due to the arrival of $\mathrm{Fe}^{2+/ 3+}$ cations, this would result in a reduction of the interparticle space of more than $50 \%$ of the initial value for surface repositories and only of $10 \%$ (of a much smaller initial value) in the case of deep seated disposal. Therefore the reaction on the particle level, on which a major part of the reactivity in surface barriers is located, is very low in a deep seated disposal site. Therefore expression (3) (Table 2) will remain close to unity in these conditions.

\subsection{TOT/TO level}

Of all considered levels, changes on the TO/TOT level will cause the greatest change in geomechanical properties. In surface civil engineering applications, processes on this TOT/TO level take a long history of subsequent physical and chemical reactions (hundreds to thousands of years in situ). Because changes on this level fail to be reproduced in the laboratory these have not been studied well in the past. To analyse changes on this level one can rely on natural analogues (Schmitz, 2004). Although one does not need to fear reactions on the particle and interlayer level as was shown above, the smallest level, the TOT/TO level, can be modified in these waste confinement scenarios due to, e.g. radiation (Plötze et al., 2003; Corbett et al., 1963). In this case expression (1) (Table 2) will become larger than 1. Irradiation is known to modify the crystalline structure of the clay. Modifications on this TOT/TO level cause the largest change in geomechanical properties. In this scenario case (V) could apply: loss of properties characteristic of clays, such as a low hydraulic conductivity!

\section{Discussion}

Chemical and physical stress, do they lead to mineral alteration and unfavourable changes of the hydro-mechanical properties of clay barriers?
A method to assess the modification potential was introduced based on three different levels. Depending on the scale on which changes occur, these changes are:

- fast (particle level), but produce only minor modifications of properties as, e.g. the hydraulic conductivity;

- slow, but produce large changes in hydro-mechanical properties (mineral alteration on the interlayer level) or change the consistency of clays completely (changes on the TOT/TO level, slowest reactions normally not relevant in most civil engineering applications).

Changes on the particle and interlayer level are known from surface civil engineering construction and have therefore been studied intensively. Considering the stress level in underground repositories it has been shown that these changes will be strongly reduced or absent. Changes on the TOT/TO level (which cause the largest modifications of hydro-mechanical properties of clays) due to radiation cannot be excluded. To guarantee a safe disposal it must be shown that changes on the TOT/TO level (often neglected in research programmes) due to, e.g. radiation are manageable.

\section{Conclusion}

To summarise one can state that the occurrence of well studied modifications of the hydro-mechanical properties such as the transport of metal ions into the clay mass will face the large inaccessibility of the clay as well on the particle as the interlayer level. The greatest attention should therefore be paid to changes on the often neglected and smallest level on which a destructuring of the basic units of the clay could occur. Future research should focus on this aspect.

\section{References}

Bolt, G.H., 1956. Physico-chemical analysis of the compressibility of pure clays. Géotechnique 6, 86-93. 
Corbett, W.J., Burson, J.H., Young, R.A., 1963. Gamma-irradiation of kaolinite. Clays and clay minerals. Earth Science Series 12, 344-355.

Di Maio, C., 1996. Exposure of bentonite to salt solution: osmotic and mechanical effects. Géotechnique 46, 695-707.

Fam, M., Dusseault, M.B., 1999. Determination of the reactivity of clayfluid systems using liquid limit data. Canadian Geomechanical Journal 36, 161-165.

Kohler, E., 1988. Beständigkeit mineralischer Dichtstoffe gegenüber organischen Prüfflüssigkeiten. Abfallwirtschaft in Forschung und Praxis 30, 117-124

Komodromos, A., Göttner, J.J., 1988. Beeinflussung von Tonen durch Chemikalien, Teil II Gefüge- und Festigkeitsuntersuchungen. Müll und Abfall 12, 552-562.

Lagaly, G., 1993. Reaktionen der Tonminerale. In: Jasmund, K., Lagaly, G. (Eds.), Tonminerale und Tone. Steinkopff Verlag, Darmstadt, pp. 89-167.

Mitchell, J.K., 1993. Fundamentals of Soil Behavior, second ed. John Wiley \& Sons Inc.

Morgenstern, N.R., Tchalenko, J.S., 1967. The optical determination of preferred orientation in clay and its application to the study of microstructure in consolidated kaolin I and II. In: Proceedings of the Royal Society of London, Series A. Mathematical and Physical Sciences 300, 218-234 and 235-250.

Müller-Vonmoos, M., Kohler, E.E., 1993. Geotechnik und Entsorgung. In: Jasmund, K., Lagaly, G. (Eds.), Tonmineralogie und Tone. Steinkopff, Darmstadt, pp. 312-357.

Plötze, M., Kahr, G., Hermanns-Stengele, R., 2003. Alteration of clay minerals-gamma-irradiation effects on physicochemical properties. Applied Clay Science 23, 195-202.

Prinz, H., 1997. Abriß der Ingenieurgeologie. Ferdinand Enke Verlag, Stuttgart.

Schmitz, R.M., 2000. Experimental shear deformation of thinly bedded clay and sand layers. Memoirs of the Centre of Engineering Geology in the Netherlands, 199.
Schmitz, R.M., 2004. Nano-Engineering Geology of clay-leachate interactions. Institute of Mechanical and Civil Engineering. Université de Liège. Dr-Ap. Sc., thesis.

Schmitz, R.M., van Paassen, L.A., 2003. The decay of the liquid limit of clays with increasing salt concentration. Ingeokring Newsletter, published by the Dutch association of Engineering geology 9, 10 14.

Schmitz, R.M., Schroeder, C., Charlier, R., 2002. A correlation between clay mineralogy and Atterberg limits. In: Proceedings of the International Workshop of Young Doctors in Geomechanics. Editors V. De Gennaro and Pierre Delage. December 4th-6th 2002. Ecole Nationale des Ponts et Chaussées, 27-30.

Schmitz, R.M., Schroeder, C., Charlier, R., 2003a. Influence of microstructure on geotechnical properties of clays. Springer Proceedings in Physics 93, 89-100.

Schmitz, R.M., Schroeder, C., Bolle, A., Thorez, J., Charlier, R., 2003b. Änderung der geotechnischen und mineralogischen Eigenschaften natürlicher Tone durch Einwirkung von Deponiesickerwasser. Müll und Abfall 35, 635-639.

Schmitz, R.M., Schroeder, C., Charlier, R., 2004a. Chemo-mechanical interactions in clay: a correlation between clay mineralogy and Atterberg limits. Applied Clay Sciences 26, 351-358.

Schmitz, R.M., Schroeder, C., Charlier, R., 2004b. Using the complete engineering geological nano spectrum to assess the performance of clay Barriers. Lecture Notes in Earth Sciences 104, 236-243.

Schmitz, R.M., Schroeder, C., Charlier, R., 2004c. L'effet des polluants sur le comportement géomécanique des argiles: une approche généralisée. Journées Nationales de Géotechnique et de Géologie de l'Ingénieur, Lille, pp. 163-173.

van Paassen, L.A., 2002. The influence of pore fluid salinity on the consolidation behaviour and undrained shear strength development of clayey soils. Memoirs of the Centre of Engineering Geology in the Netherlands, 216. 